\title{
BMJ Open Testosterone in advance age: a New Zealand longitudinal cohort study: Life and Living in Advanced Age (Te Puāwaitanga o Ngā Tapuwae Kia Ora Tonu)
}

Martin J Connolly, ${ }^{1}$ Ngaire Kerse, ${ }^{2}$ Tim Wilkinson, ${ }^{3}$ Oliver Menzies, ${ }^{4}$ Anna Rolleston, ${ }^{2}$ Yih Harng Chong, ${ }^{3}$ Joanna B Broad, ${ }^{1}$ Simon A Moyes, ${ }^{2}$ Santosh Jatrana, ${ }^{5,6}$ Ruth Teh ${ }^{2}$

To cite: Connolly MJ, Kerse N, Wilkinson T, et al. Testosterone in advance age: a New Zealand longitudinal cohort study: Life and Living in Advanced Age (Te Puāwaitanga o Ngā Tapuwae Kia Ora Tonu). BMJ Open 2017;7:e016572. doi:10.1136/ bmjopen-2017-016572

- Prepublication history and additional material for this paper are available online. To view these files, please visit the journal online (http://dx.doi. org/10.1136/bmjopen-2017016572).

Received 28 February 2017 Revised 6 August 2017

Accepted 9 August 2017

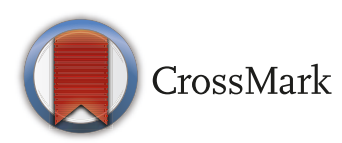

For numbered affiliations see end of article.

\section{Correspondence to}

Professor Martin J Connolly; martin.connolly@waitematadhb. govt.nz

\section{ABSTRACT}

Objectives Serum testosterone (T) levels in men decline with age. Low $T$ levels are associated with sarcopenia and frailty in men aged $\geq 80$ years. T levels have not previously been directly associated with disability in older men. We explored associations between $\mathrm{T}$ levels, frailty and disability in a cohort of octogenarian men.

Setting Data from all men from Life and Living in Advanced Age Cohort Study in New Zealand, a longitudinal cohort study in community-dwelling older adults.

Participants Community-dwelling ( $\geq 80$ years) adult men excluding those receiving $\mathrm{T}$ treatment or with prostatic carcinoma.

Outcomes measures Associations between baseline total testosterone (TT) and calculated free testosterone (fT), frailty (Fried scale) and disability (Nottingham Extended Activities of Daily Living scale (NEADL)) (baseline and 24 months) were examined using multivariate regression and Wald's $\chi^{2}$ techniques. Subjects with the lowest quartile of baseline TT and fT values were compared with those in the upper three quartiles.

Results Participants: 243 men, mean (SD) age 83.7 (2.0) years. Mean (SD) $T T=17.6$ (6.8) $\mathrm{nmol} / \mathrm{L}$ and $\mathrm{fT}=225.3$ (85.4) pmol/L. On multivariate analyses, lower TT levels were associated with frailty: $\beta=0.41, p=0.017$, coefficient of determination $\left(R^{2}\right)=0.10$ and disability (NEADL) $\left(\beta=-1.27, p=0.017, R^{2}=0.11\right)$, low haemoglobin $\left(\beta=-7.38, p=0.0016, R^{2}=0.05\right)$, high fasting glucose $\left(\beta=0.38, p=0.038, R^{2}=0.04\right)$ and high $C$ reactive protein (CRP) $\left(\beta=3.57, p=0.01, R^{2}=0.06\right)$. Low $\mathrm{fT}$ levels were associated with frailty $\left(\beta=0.39, p=0.024, R^{2}=0.09\right)$ but not baseline NEADL $\left(\beta=-1.29, p=0.09, R^{2}=0.09\right)$. Low fT was associated with low haemoglobin $(\beta=-7.83, p=0.0008$, $\left.R^{2}=0.05\right)$ and high $\operatorname{CRP}\left(\beta=2.86, p=0.04, R^{2}=0.05\right)$. Relationships between baseline TT and fT, and 24-month outcomes of disability and frailty were not significant. Conclusions In men over 80 years, we confirm an association between $\mathrm{T}$ levels and baseline frailty scores. The new finding of association between T levels and disability is potentially relevant to debates on $T$ supplementation in older men, though, as associations were not present at 24 months, further work is needed.

\section{Strengths and limitations of this study}

- Representative cohort study with well-characterised subjects.

- Employed trained personnel and validated measures.

- Extends information on associations of serum testosterone levels to very old men.

- Associations reported cannot be assumed to be causal.

- Possible selection bias, as some study subjects declined blood tests.

- No longitudinal analysis of serum testosterone levels.

\section{INTRODUCTION}

Serum testosterone (T) levels decline with age in healthy men, and although there may be some degree of cohort effect, ${ }^{1}$ it is generally accepted that this is a genuine age-related phenomenon that continues up to extreme longevity (age 90+) in populations studied..$^{2-4}$ Decline in circulating $\mathrm{T}$ level is influenced by Leydig cell attrition and other pathological and physiological factors that affect the hypothalamic-pituitary-testicular axis. ${ }^{5}$ Though the clinical and functional consequences of this decline are less clear, age-related low $\mathrm{T}$ levels have been associated with an increased prevalence of sarcopenia $^{56}$ and with the frailty syndrome. ${ }^{578}$ These latter associations have, however, been demonstrated mainly in those under 80 years of age, with few studies in men over the age of 80 years. ${ }^{78}$ Further, there has been little research directed at examining a potential association of $\mathrm{T}$ levels with long-term disability in older men, although some (not all) studies that examined activity levels, falls 
and quality of life scales against $\mathrm{T}$ levels have implied a possible relationship with disability. ${ }^{9-13}$

There remains uncertainty about the role of $\mathrm{T}$ in late life. Supplementation for older men with low $\mathrm{T}$ levels has not necessarily been beneficial to sarcopenia and frailty. Though short-term supplementation studies have confirmed improvements in muscle bulk/lean body mass, muscle power (in some studies but not all), physical and function tests/activity levels, ${ }^{514-18}$ the clinical value of these improvements is unknown. Further, despite evidence that short-term treatment does not produce prolonged benefit, ${ }^{17}$ there are no really longterm studies. Very few studies were found with a duration of 3 years: one of these demonstrated no effect of $\mathrm{T}$ on muscle strength. ${ }^{516}$ Another reported an increase in grip strength ${ }^{19}$ A very recent study, also over 3 years, showed that $\mathrm{T}$ supplementation improved some (not all) measures of muscle strength, but that any beneficial effect 'appeared to wane over time' ${ }^{20}$ Important concerns about longer-term safety remain, most particularly with regard to known or (in the absence of definitive studies) potential behavioural and other side effects (erythrocytosis, cardiovascular events and possible increased risk of prostate cancer) of $\mathrm{T}$ supplementation, ${ }^{521}$ though more recent extensive reviews have been relatively reassuring regarding potential medium-term and long-term potential cardiovascular and prostate cancer risks. ${ }^{223}$

Life and Living in Advanced Age Cohort Study in New Zealand (LiLACS NZ): Te Puāwaitanga o Ngā Tapuwae Kia Ora Tonu is a population-based cohort study of Māori (indigenous people of New Zealand) and non-Māori of advanced age, including those in long-term care. In the present paper, we examine whether serum $\mathrm{T}$ levels at baseline are associated with validated outcome measures of frailty and of extended activities of daily living (EADL) in men enrolled in LiLACS NZ, and to assess any association of baseline hormone levels with change in these outcome measures 2 years later. Our rationale was to add to the limited knowledge around the association between $\mathrm{T}$ levels and frailty in very old men and to examine relationships between $\mathrm{T}$ levels and EADL.

\section{METHODS}

\section{Subjects and study methods}

The full methodology of the LiLACS NZ is described elsewhere. ${ }^{24}$ Briefly, two cohorts of similar size, Māori and non-Māori, were enrolled. Potential participants were those born between 1 January and 31 December 1925 (aged 85 years in 2010) for non-Māori and between 1 January 1920 and 31 December 1930 (aged 80-90 years in 2010) for Māori. People meeting these criteria and living within the Lakes (excluding Taupo) region or Bay of Plenty District Health Board areas during the 2010 enrolment year were eligible. The Northern X Regional Ethics Committee of New Zealand granted ethics approval for the longitudinal study in December 2009 (NTX/09/09/088), and written informed consent was obtained from all participants. Considerable efforts were made to ascertain as complete a sample as possible of those eligible and kaupapa Māori methods ${ }^{25}$ were used to enable Māori participation. For the current study, all male participants who gave a blood sample (optional) were potentially eligible except those with known diagnosis of prostatic carcinoma or those receiving $\mathrm{T}$ supplementation. Given the wide-scoped methodology of the LiLACS NZ study, no separate power analysis for T levels was conducted.

Baseline measures (wave 1) were collected by trained interviewers and research nurses ${ }^{26}$ using standardised techniques: a structured face-to-face standardised questionnaire, a health assessment and blood tests and a review of general practice medical records for diagnosed medical conditions. Blood samples (cholesterol, glucose, haemoglobin, high-sensitive $\mathrm{C}$ reactive protein (CRP) and total testosterone (TT)) were collected by a registered nurse or local laboratory service as a morning (fasting) sample at wave 1 . TT levels were measured by competitive ELISA in duplicate (R\&D systems, Minneapolis, USA) with detection limit of $0.041 \mathrm{ng} / \mathrm{mL}$. The manufacturer's reported intra-assay and interassay coefficients of variation were $4.0 \%$ and $6.8 \%$, respectively. Free testosterone (fT) was calculated. ${ }^{27}$ Smoking status and estimated alcoholic drinks per annum were ascertained by self-report. Blood pressure (digital device), height (stadiometer) and weight (Tanita scales) were measured by a trained research nurse at baseline. The mean of the last two of three blood pressure measures was used. The Charlson Index of Comorbidity ${ }^{28}$ was calculated from a combination of self-report, general practitioner medical record review and from hospital records from the previous 12 months using ICD-10 codes.$^{29}$ Further details are available from the authors on request.

Participants were reinterviewed annually: this report uses the baseline data (wave 1) and that from two follow-ups (waves 2 and 3) completed at 12 and 24 months.

\section{Outcomes}

The following provides a brief résumé of protocols, which are reported in detail elsewhere. ${ }^{24}$ Fried Frailty Index ${ }^{30}$ was measured with variables collected as follows: weakness grip strength measured by lowest $20 \%$ (by gender, ethnic group, body mass index (BMI)); poor endurance-from the question "During the past fourweeks (have you) had a lot of energy none of the time or little of the time"; slowness of walking speed from 3 metre walk test of the Short Physical Performance Battery protocol-the slowest 20\% (by gender, ethnic group, height); low activity by Physical Activity Scale for the Elderly scores-the lowest $20 \%$ by gender and ethnic group; unintentional weight loss $\geq 5 \mathrm{~kg}$ in previous 6 months. The Fried Index is scored 0 to 5 , a score of 0 corresponding to a 'robust' individual, scores of 1 or 2 indicating a 'prefrail' individual and scores of 3 or higher indicating a 'frail' individual. 
The Nottingham Extended Activities of Daily Living Index (NEADL) ${ }^{31}$ was collected for all subjects. The SF-12 Mental Health Component summary subscore (MHC) and Physical Health Component subscore (PHC) were used to assess health-related quality of life (HRQOL) ${ }^{32}$ NEADL is scored between 0 and 22 points, higher scores indicating less disability. PHC and MHC are scored from 0 to 100 , higher scores indicating better quality of life.

\section{Statistical methods}

Age was treated as a continuous variable. Both total and fT measures were dichotomised into lowest quartile versus the upper three quartiles. ${ }^{33}$ The association between TT and $\mathrm{fT}$ and outcomes of NEADL, SF-12 PHC, MHC and the Fried scale was assessed using age-adjusted and ethnicity-adjusted generalised linear models. All models assumed normal $\mathrm{T}$ distributions. These were checked against models controlling for potential confounders including smoking status, cholesterol, haemoglobin, blood pressure, alcoholic drinks per annum and Charlson Index. Change in NEADL, SF-12 PHC, MHC and the Fried scale over 1 and 2 years of follow-up were also modelled, with change in outcome (NEADL, frailty or HRQOL) as the dependent variable and $\mathrm{T}$ level at baseline as the independent variable. Models were controlled for age, ethnicity initially (multivariate model) and then smoking, cholesterol, haemoglobin, blood pressure and drinking in an extended model. To consider differences between men who did, versus did not, provide a blood sample we used 40 iterations of multiple imputation for the NEADL complex model, the PHC complex model, the MHC complex model and the Fried complex model.

\section{RESULTS}

Subjects (table 1) comprised 390 men with mean (SD) age of 83.7 (2.2) years at baseline. Of these 147 were ineligible: 82 completed core questions only which did not include blood tests, 29 consented but did not give a blood sample and 24 declined blood tests on their consent form. A further 12 were excluded; 9 because of known prostatic carcinoma, 2 being treated with cyproterone acetate and 1 with another prostate injury.

Overall, at baseline, 243 (mean (SD) age of 83.7 (2.0) years, 83 Māori and 160 non-Māori) were included. Those consenting to blood tests were healthier and less frail than those that did not: of those not giving a blood sample, $13 \%$ were in residential care compared with $1 \%$ of those that did give a sample $(\mathrm{p}<0.0001)$; of those giving a blood sample, $97 \%$ showered independently compared with $88 \%$ of those not giving a sample $(\mathrm{p}=0.011)$ and of those who gave a blood sample, $5 \%$ died within 12 months compared with $8 \%$ of those not giving blood $(\mathrm{p}=0.20)$. More Māori declined blood sampling (59\% Māori, 42\% non-Māori declined, $\mathrm{p}<0.0001)$.

Mean (SD) Charlson Index was 6.52 (5.92). Ten per cent were frail (scoring 3+ on the Fried Index), 37\% were prefrail and $53 \%$ were not frail. Mean NEADL score was 17.8 (SD 3.4) (maximum score=22, indicating no disability). Over time 203 of the 243 completed the 1-year follow-up, 171 completed the 2-year follow-up.

As described, the Fried Index is a five-point scale with 1 point given for each of five markers of frailty. No one in our sample scored 5 and most scored 0 . The models presented treat the Fried score as a continuous variable, although the ordinal was a better fit (and gave a $p$ value for $\mathrm{fT}$ of 0.031 and TT of 0.021 ). Beta ( $\beta$ ) in this model is the estimated $\log$ OR of scoring in the Fried 0 vs $>0$, but is also the estimated $\log$ OR of scoring in the Fried 0 or 1 vs $>1$, etc (the link is $\log$ because the Fried Index is modelled as having a negative binomial distribution). At baseline, the mean (SD) of TT was $17.6(6.8) \mathrm{nmol} / \mathrm{L}$ and of fT was $225.3(85.4) \mathrm{pmol} / \mathrm{L}$. The lowest quartiles were below $13.3 \mathrm{nmol} / \mathrm{L}$ for TT and below $175.1 \mathrm{pmol} / \mathrm{L}$ for $\mathrm{fT}$ ). On analyses adjusting for age and ethnic group, lower TT levels were independently associated with both frailty (Fried score; F-statistic $=9.72, \mathrm{p}=0.0021$ ) and disability (NEADL score; F-statistic $=6.14, \mathrm{p}=0.014$ ) at baseline.

TT level was also positively associated with haemoglobin level $(\mathrm{p}=0.0016)$ and negatively associated with fasting glucose $(p=0.038)$ and CRP $(p=0.010)$. $f T$ was also positively associated with haemoglobin $(\mathrm{p}=0.0008)$ and negatively associated with CRP $(\mathrm{p}=0.04)$. TT or $\mathrm{fT}$ was not associated with ethnicity (Māori/non-Māori), total cholesterol, blood pressure, BMI, waist circumference, alcohol consumption, tobacco smoking or quality of life at baseline. Low fT levels were associated with Fried score ( $\mathrm{p}=0.0034)$ but not NEADL $(\mathrm{p}=0.07)$.

In multivariate models (tables 2 and 3 ), when controlling for age, ethnicity, smoking status, total cholesterol level, haemoglobin, blood pressure, alcoholic drinks per annum and Charlson score, lower TT remained independently associated with Fried score $(\mathrm{p}=0.017)$ and with NEADL $(p=0.017)$; low $f T$ was independently associated with Fried score $(p=0.024)$ but not with NEADL $(\mathrm{p}=0.093)$.

Longitudinal analyses showed no association of either baseline TT or fT levels with the change in either Fried score or NEADL levels over time. The wave 2 interview was on average 363 (SD 31) days and the wave 3 interview 734 (SD 40) days, respectively, after the wave 1 interview. Sensitivity analyses were conducted using 40 iterations of multiple imputation; conclusions did not change.

\section{DISCUSSION}

The age-related decline in serum $\mathrm{T}$ levels in healthy men is now generally recognised. ${ }^{5}$ Though we do not have a younger group for comparison, our results add to the currently limited literature extending evidence of low $\mathrm{T}$ levels beyond the age of 80 years. However, the lack of a fully validated normative range for $\mathrm{T}$ in men over 80 years is due to an imperfect understanding about late-onset hypogonadism-a very recently established range being based on assessments in approximately 300 individuals in total. ${ }^{34}$ Hence the current study adds to 
Table 1 Demographics of sample

\begin{tabular}{|c|c|c|c|c|c|}
\hline & \multicolumn{2}{|c|}{ Total testosterone } & \multicolumn{2}{|c|}{ Free testosterone } & \multirow[b]{2}{*}{ Total } \\
\hline & Lowest quartile & Other quartiles & Lowest quartile & Other quartiles & \\
\hline Age (years) & $83.8(1.8)$ & $83.6(2.1)$ & $83.8(1.8)$ & $83.6(2.0)$ & $83.7(2.0)$ \\
\hline Height (m) & $1.7(0.06)$ & $1.7(0.06)$ & $1.7(0.06)$ & $1.7(0.06)$ & $1.7(0.06)$ \\
\hline Weight (kg) & $81.6(16.1)$ & $79.7(12.1)$ & $81.7(15.8)$ & 79.7 (12.2) & $80.2(13.2)$ \\
\hline Body mass index $\left(\mathrm{kg} / \mathrm{m}^{2}\right)$ & $28.3(5.2)$ & $27.7(4.2)$ & $28.4(5.2)$ & $27.7(4.2)$ & $27.9(4.5)$ \\
\hline Haemoglobin $(\mathrm{g} / \mathrm{L})$ & $132.4(16.8)$ & $139.7(15.0)$ & $132(16.6)$ & $139.9(15.0)$ & $137.9(15.8)$ \\
\hline Serum cholesterol (mmol/L) & $4.62(0.97)$ & $4.66(0.95)$ & $4.67(0.97)$ & $4.64(0.96)$ & $4.65(0.96)$ \\
\hline Serum triglycerides (mmol/L) & $1.42(0.62)$ & $1.31(0.79)$ & $1.39(0.63)$ & $1.32(0.79)$ & $1.34(0.75)$ \\
\hline High density lipoprotein (mmol/L) & $1.40(0.34)$ & $1.40(0.34)$ & $1.41(0.33)$ & $1.40(0.35)$ & $1.40(0.34)$ \\
\hline Low density lipoprotein (mmol/L) & $2.57(0.85)$ & $2.67(0.81)$ & $2.63(0.85)$ & $2.65(0.81)$ & $2.64(0.82)$ \\
\hline Glycated haemoglobin (mmol/L) & $39.5(12.4)$ & $37.9(7.9)$ & 39 (12.3) & $38.1(8.0)$ & $38.3(9.2)$ \\
\hline Serum glucose (mmol/L) & $5.93(1.73)$ & $5.53(1.01)$ & $5.85(1.50)$ & $5.55(1.13)$ & $5.63(1.23)$ \\
\hline Systolic blood pressure (BP) (mm Hg) & $144.3(23.0)$ & $146.6(21.5)$ & $142.7(22.9)$ & $147.1(21.4)$ & $146(21.9)$ \\
\hline Diastolic BP (mm Hg) & $80.8(14.0)$ & $82.2(12.8)$ & $80.2(14.4)$ & $82.4(12.6)$ & $81.9(13.1)$ \\
\hline $\begin{array}{l}\text { Estimated number of alcoholic drinks } \\
\text { per annum }\end{array}$ & $222.1(245.8)$ & $266.3(280.0)$ & $235.2(242.0)$ & $262.2(281.6)$ & $255.8(272.4)$ \\
\hline Number of medications & $6.53(3.41)$ & $4.72(3.42)$ & $6.11(3.15)$ & $4.86(3.55)$ & $5.16(3.50)$ \\
\hline Māori (\%) & 19 (31.2) & 64 (35.2) & $20(32.8)$ & $63(34.6)$ & 83 (34.2) \\
\hline Currently smokes (\%) & $4(6.6)$ & $15(8.2)$ & $4(6.6)$ & $15(8.2)$ & $19(7.8)$ \\
\hline Congestive heart failure (\%) & $19(31.2)$ & $40(22.0)$ & $18(29.5)$ & $41(22.5)$ & $59(24.3)$ \\
\hline Had CVA (\%) & $14(23.0)$ & $42(23.1)$ & $13(21.3)$ & $43(23.6)$ & $56(23.1)$ \\
\hline Peripheral vascular disease (\%) & $11(18.0)$ & $24(13.2)$ & $12(19.7)$ & $23(12.6)$ & $35(14.4)$ \\
\hline Hypertensive (\%) & $52(85.3)$ & $161(88.5)$ & $53(86.9)$ & $160(87.9)$ & $213(87.7)$ \\
\hline Asthma (\%) & $11(18.0)$ & $12(6.6)$ & $10(16.4)$ & $13(7.1)$ & $23(9.5)$ \\
\hline Osteoporosis (\%) & $4(6.6)$ & $6(3.3)$ & 5 (8.2) & $5(2.8)$ & $10(4.1)$ \\
\hline Chronic lung disease (\%) & $14(23.0)$ & $33(18.1)$ & $14(23.0)$ & $33(18.1)$ & 47 (19.3) \\
\hline Diabetes (\%) & $14(23.0)$ & $25(13.7)$ & $14(23.0)$ & $25(13.7)$ & $39(16.1)$ \\
\hline Dementia (\%) & $1(1.6)$ & 7 (3.9) & $1(1.6)$ & 7 (3.9) & $8(3.3)$ \\
\hline Rheumatoid arthritis (\%) & $9(14.8)$ & $24(13.2)$ & $8(13.1)$ & $25(13.7)$ & $33(13.6)$ \\
\hline Osteoarthritis (\%) & $23(37.7)$ & $47(25.8)$ & $23(37.7)$ & $47(25.8)$ & $70(28.8)$ \\
\hline Coronary artery disease (\%) & $36(59.0)$ & $76(41.8)$ & $33(54.1)$ & $79(43.4)$ & $112(46.1)$ \\
\hline Atrial fibrillation (\%) & $16(26.2)$ & $50(27.5)$ & $17(27.9)$ & $49(26.9)$ & $66(27.2)$ \\
\hline Anaemia (\%) & $28(45.9)$ & $43(23.6)$ & $28(45.9)$ & $43(23.6)$ & $71(29.2)$ \\
\hline
\end{tabular}

a relatively small body of knowledge on this topic. The clinical and functional significance of this age-related decline, and any need for possible $\mathrm{T}$ supplementation to prevent, ameliorate or treat its putative effects remain controversial. The debate in this area has thus far largely focused on the association of $\mathrm{T}$ decline with frailty. ${ }^{78} 1235$ Although some authors have also addressed quality of life and physical performance, including a possible association of $\mathrm{T}$ decline with disability, ${ }^{9-14}$ as far as we are aware ours is the first study to demonstrate that lower $\mathrm{T}$ is associated with disability in a population in advanced age unselected for organ-specific diseases. ${ }^{28} 3536$ Despite overall $\mathrm{T}$ levels in our sample being a little higher than those previously reported for previous studies in older men,${ }^{1-4}$ our ${ }^{34}$ results clearly indicate a strong relationship between lower TT levels at baseline and baseline disability measured on a well-validated instrumental activities of daily living scale, as well as hinting at $(\mathrm{p}=0.07)$ a similar relationship between calculated baseline fT levels and baseline disability scores. There was also a strong association between baseline $\mathrm{T}$ and baseline frailty scores. Given that frailty is a strong predictor of disability and other adverse outcomes ${ }^{28}$ this is perhaps unsurprising, but it does potentially add some weight (despite our demonstrated lack of relationship between baseline $\mathrm{T}$ levels and frailty or disability measures at 24 months) to the argument for (long-term) trials of $\mathrm{T}$ supplementation in older frail men with low or low/normal T levels ${ }^{17}{ }^{21}$; 


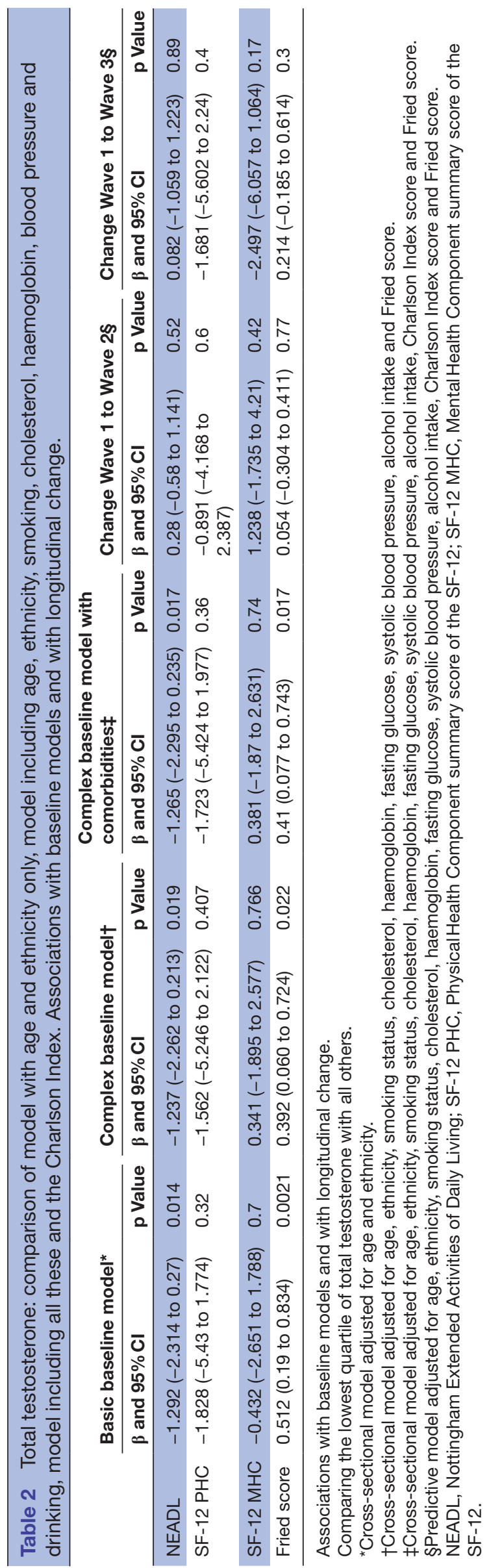

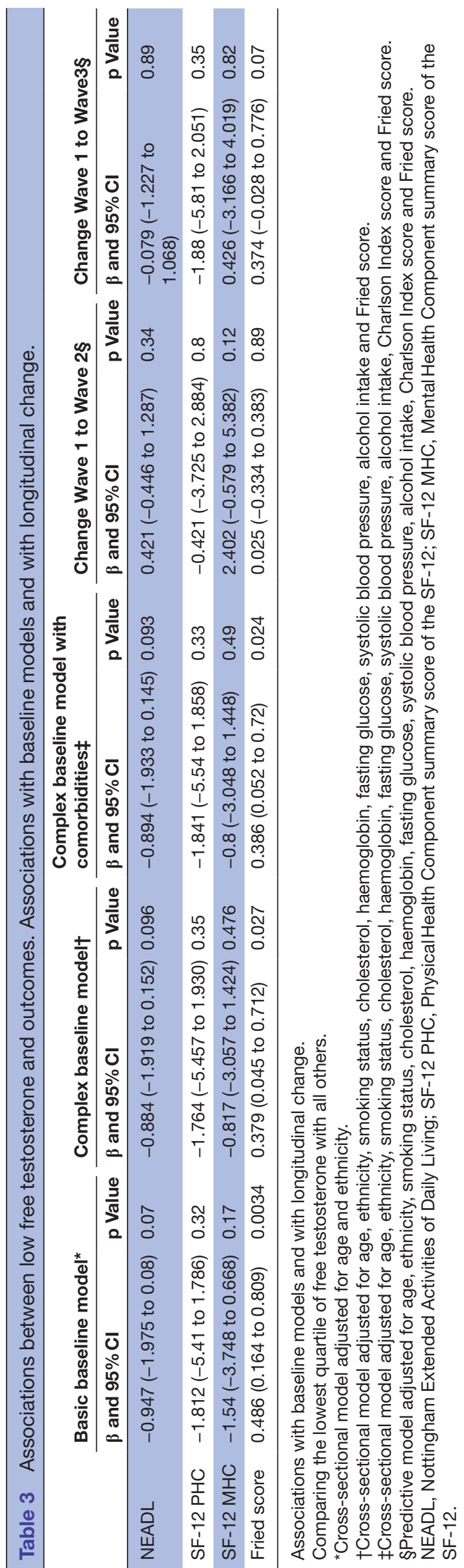


amelioration, postponement, prevention or treatment of disability has potential for greater and more immediate personal (patient) and societal benefit than amelioration, postponement, prevention or treatment of frailty. This may be particularly so for some frail men in whom small gains in strength and function may be adequate to maintain or restore independence-though what criteria are employed to identify such men remain to be elucidated. ${ }^{36}$ There has been recent interest in $\mathrm{T}$ supplementation in the treatment of unexplained anaemia in older men. ${ }^{37}$ Given that chronic anaemia may contribute to frailty, our confirmation of the recognised association of $\mathrm{T}$ levels and haemoglobin levels is potentially important.

The association between lower $\mathrm{T}$ levels and disability was observed at baseline, and no prediction of change in function related to T level was observed. A similar discrepancy between cross-sectional and longitudinal findings regarding $\mathrm{T}$ and frailty (but not disability) was revealed in a study by Cawthon $e t a l,{ }^{38}$ who thus hypothesised that either: (1) there is no relationship between T levels and frailty, that is, that their cross-sectional associations were in fact a chance association. In the current study (like that of Cawthon $e t a l$ ) we believe that we have included most potential covariates, and we thus agree with Cawthon that this explanation is not likely, though of course, as Cawthon also acknowledged, we cannot exclude such a possibility in what is purely an observational study; (2) T is truly related to frailty and disability, but that the longitudinal associations do not reach statistical significance because of limited power to detect an association due to inadequate sample size (the sample size at 24 months being smaller than the baseline sample).

Though age-related sarcopenia, frailty and subsequent disability are well recognised even in otherwise healthy older men, ${ }^{26}$ chronic disease and especially multiple chronic comorbidity, is a major risk factor for both frailty and disability. Chronic diseases are known to be associated with low T levels. ${ }^{52} 3536 \mathrm{~T}$ levels may fall further during acute exacerbations of these chronic conditions in relation to severity of exacerbation. ${ }^{36}$ Although our subjects were medically well (ie, not institutionalised or hospitalised and not acutely ill) at the time of T estimation, their levels of comorbidity were relatively high, with on average five conditions. ${ }^{39}$ There is thus need for studies of T levels and disability in healthy older men, as opposed to a more representative sample of a population such as LiLACS NZ. Whether trials of T supplementation, as discussed above, should, at least initially, be confined to otherwise healthy older men, or should include older men with (multiple) comorbidity $^{35}$ is a more complex issue. Further adding to the complexity is the as yet unresolved possibility, despite recent relatively reassuring data, that $\mathrm{T}$ supplementation carries the risk of major adverse effects.

Our study was part of a well-conducted, representative population cohort study in which subjects were carefully characterised. It employed well-validated measures administered by trained personnel. The associations we demonstrated between $T$ levels and glucose, haemoglobin and CRP levels confirm those recognised previously and are thus reassuring. ${ }^{2}$

Our study also has weaknesses. First, as discussed above, though we attempted to allow for this statistically, the effect of comorbidity on the relationship between T levels and disability (and frailty) cannot be fully elucidated, and the associations reported cannot be regarded as causal. Second, many of our potentially eligible subjects did not contribute a blood sample. Although this increased the selection bias of our sample, it may have militated against any effect of multiple comorbidity, as those consenting to blood tests were a healthier sample than those not. Third, as all of our subjects were aged 85 years (non-Māori) or 80-90 years (Māori), we were unable to examine any differential age-related cohort effect on T levels. This has, however, been previously well characterised by others. ${ }^{1-4}$ Fourth (and similarly), we assessed $\mathrm{T}$ levels at only one time-point, thus precluding any longitudinal analysis of $\mathrm{T}$ levels-though again this has been previously characterised. ${ }^{23}$ We were not able to demonstrate that baseline TT and $\mathrm{fT}$ predict change in frailty or disability measure over 2 years. Finally, it would have been helpful to have had T measures from a comparator group of young men from the same local population, but the study methodology precluded this.

The lack of a fully validated normative range in older men for $\mathrm{T}$ is due to the lack of understanding about late-onset hypogonadism, hence this study adds to a small body of knowledge on this topic. Those with lower $\mathrm{T}$ levels relative to their peers were significantly more likely to be frail and disabled in advanced age. Further research is needed to confirm our findings, to examine these relationships in a (selected) sample of healthy men of advanced age and to examine the longitudinal value of a baseline measurement of (or decline in) serum $\mathrm{T}$ in the prediction of frailty and disability. Should these relationships be confirmed this would add weight to the argument for assessing the potential benefits and hazards of $\mathrm{T}$ supplementation in both healthy older men and older men with comorbidity.

\section{Author affiliations}

${ }^{1}$ Freemasons' Department of Geriatric Medicine, University of Auckland, Auckland, New Zealand

${ }^{2}$ School of Population Health, University of Auckland, Auckland, New Zealand ${ }^{3}$ Department of Medicine, University of Otago, Christchurch, New Zealand ${ }^{4}$ Geriatric Medicine, Auckland District Health Board, Auckland, New Zealand ${ }^{5}$ Centre for Social Impact, Faculty of Business and Law, Swinburne University of Technology, Melbourne, Australia

${ }^{6}$ University of Otago, Wellington, New Zealand

Acknowledgements The authors are grateful to all participants and investigators in LiLACS NZ. The authors are grateful to Gabrielle Peters for her assistance with manuscript preparation and formatting.

Contributors The conception of the paper was from MJC, NK and TW. All authors (MJC, NK, TW, OM, AR, YHC, JBB, SAM, SJ, RT) contributed to and approved the manuscript. NK headed and MJC assisted with grant application for funding. SAM led the statistical analyses. All authors (MJC, NK, TW, OM, AR, YHC, JBB, SAM, SJ, RT) have full access to data.

Funding All authors declare that: MJC, NK, AR, SM, JBB and RT have support from the University of Auckland and from the Health Research Council of New Zealand 
for the submitted work; TW, SJ and YHC have/had support from the University of Auckland and from the Health Research Council of New Zealand.

Disclaimer The Health Research Council (study funders) were not involved in the design, methodology, conduct or analysis of the study.

Ethics approval Northern X Regional Ethics Committee of New Zealand (NTX/09/09/088).

Provenance and peer review Not commissioned; externally peer reviewed.

Data sharing statement Data may be provided on request for specified purposes. This would require further approval by New Zealand National Ethics Committee.

Open Access This is an Open Access article distributed in accordance with the Creative Commons Attribution Non Commercial (CC BY-NC 4.0) license, which permits others to distribute, remix, adapt, build upon this work non-commercially, and license their derivative works on different terms, provided the original work is properly cited and the use is non-commercial. See: http://creativecommons.org/ licenses/by-nc/4.0/

(C) Article author(s) (or their employer(s) unless otherwise stated in the text of the article) 2017. All rights reserved. No commercial use is permitted unless otherwise expressly granted.

\section{REFERENCES}

1. Perheentupa A, Mäkinen J, Laatikainen T, et al. A cohort effect on serum testosterone levels in Finnish men. Eur J Endocrinol 2013;168:227-33.

2. Harman SM, Metter EJ, Tobin JD, et al. Longitudinal effects of aging on serum total and free testosterone levels in healthy men. The Journal of Clinical Endocrinology \& Metabolism 2001;86:724-31.

3. Feldman HA, Longcope C, Derby CA, et al. Age trends in the level of serum testosterone and other hormones in middle-aged men: longitudinal results from the Massachusetts male aging study. J Clin Endocrinol Metab 2002;87:589-98.

4. Yeap BB, Knuiman MW, Divitini ML, et al. Differential associations of testosterone, dihydrotestosterone and oestradiol with physical metabolic and health-related factors in community-dwelling men aged 17-97 years from the busselton health survey. Clin Endocrinol 2014;81:100-8.

5. Ahern T, Wu FC. New horizons in testosterone and the ageing male. Age Ageing 2015;44:188-95.

6. Köhn FM. Testosterone and body functions. Aging Male 2006;9:183-8.

7. Hyde Z, Flicker L, Almeida OP, et al. Low free testosterone predicts frailty in older men: the health in men study. J Clin Endocrinol Metab 2010;95:3165-72.

8. Travison TG, Nguyen AH, Naganathan V, et al. Changes in reproductive hormone concentrations predict the prevalence and progression of the frailty syndrome in older men: the concord health and ageing in men project. $J$ Clin Endocrinol Metab 2011;96:2464-74

9. Glintborg D, Nielsen TL, Wraae K, et al. The relationship between health-related quality of life, obesity and testosterone levels in older men. Age Ageing 2014;43:280-4.

10. Maggio M, Ceda GP, Lauretani F, et al. Gonadal status and physical performance in older men. Aging Male 2011;14:42-7.

11. Hsu B, Cumming RG, Blyth FM, et al. Longitudinal and crosssectional relationships of circulating reproductive hormone levels to self-rated health and health-related quality of life in communitydwelling older men. J Clin Endocrinol Metab 2014;99:1638-47.

12. Tajar A, Huhtaniemi IT, O'Neill TW, et al. EMAS Group. Characteristics of androgen deficiency in late-onset hypogonadism: results from the European Male Aging Study (EMAS). J Clin Endocrinol Metab 2012;97:1508-16.

13. Kurita N, Horie S, Yamazaki S, et al. Low testosterone levels, depressive symptoms, and falls in older men: a cross-sectional study. J Am Med Dir Assoc 2014;15:30-5.

14. Srinivas-Shankar U, Roberts SA, Connolly MJ, et al. Effects of testosterone on muscle strength, physical function, body composition, and quality of life in intermediate-frail and frail elderly men: a randomized, double-blind, placebo-controlled study. J Clin Endocrinol Metab 2010;95:639-50.

15. Kvorning T, Christensen LL, Madsen K, et al. Mechanical muscle function and lean body mass during supervised strength training and testosterone therapy in aging men with low-normal testosterone levels. J Am Geriatr Soc 2013;61:957-62.

16. Snyder PJ, Peachey H, Hannoush P, et al. Effect of testosterone treatment on body composition and muscle strength in men over 65 years of age. J Clin Endocrinol Metab 1999;84:2647-53.

17. O'Connell MD, Roberts SA, Srinivas-Shankar U, et al. Do the effects of testosterone on muscle strength, physical function, body composition, and quality of life persist six months after treatment in intermediate-frail and frail elderly men? J Clin Endocrinol Metab 2011;96:454-8.

18. Snyder PJ, Bhasin S, Cunningham GR, et al. Effects of testosterone treatment in older men. New England Journal of Medicine 2016;374:611-24.

19. Page ST, Amory JK, Bowman FD, et al. Exogenous testosterone (T) alone or with finasteride increases physical performance, grip strength, and lean body mass in older men with low serum T. J Clin Endocrinol Metab 2005;90:1502-10.

20. Storer TW, Basaria S, Traustadottir T, et al. Effects of testosterone supplementation for 3 years on muscle performance and physical function in older men. J Clin Endocrinol Metab 2017;102:583-93.

21. Maggio M, Lauretani F, Ceda GP. Sex hormones and sarcopenia in older persons. Curr Opin Clin Nutr Metab Care 2013;16:3-13.

22. Morgentaler A, Miner MM, Caliber M, et al. Testosterone therapy and cardiovascular risk: advances and controversies. Mayo Clin Proc 2015;90:224-51.

23. Khera M, Crawford D, Morales A, et al. A new era of testosterone and prostate cancer: from physiology to clinical implications. Eur Urol 2014;65:115-23.

24. Kerse N, Teh R, Moyes SA, et al. Cohort profile: te puawaitanga o nga tapuwae kia ora tonu, life and living in advanced age: a cohort study in new zealand (LiLACS NZ). Int J Epidemiol 2015;44:1823-32.

25. Cram F, Phillips H, Tipene-Matua B, et al. A 'parallel process'? beginning a constructive conversation about a maori methodology. J Bioeth Inq 2004;1:14-19.

26. Hayman KJ, Kerse N, Dyall L, et al. Life and living in advanced age: a cohort study in new zealand-e puawaitanga o nga tapuwae kia ora tonu, LiLACS NZ: study protocol. BMC Geriatr 2012;12:33.

27. Sartorius G, Ly LP, Sikaris K, et al. Predictive accuracy and sources of variability in calculated free testosterone estimates. Ann Clin Biochem 2009;46:137-43.

28. Charlson ME, Pompei P, Ales KL, et al. A new method of classifying prognostic comorbidity in longitudinal studies: development and validation. J Chronic Dis 1987;40:373-83.

29. Crooks CJ, West J, Card TR. A comparison of the recording of comorbidity in primary and secondary care by using the charlson Index to predict short-term and long-term survival in a routine linked data cohort. BMJ Open 2015;5:e007974.

30. Fried LP, Tangen CM, Walston J, et al. Cardiovascular Health Study Collaborative Research Group. Frailty in older adults: evidence for a phenotype. J Gerontol A Biol Sci Med Sci 2001;56:M146-M157.

31. Nouri FM, Lincoln NB. An extended activities of daily living scale for stroke patients. Clin Rehabil 1987;1:301-5.

32. Jakobsson U. Using the 12-item short form health survey (SF-12) to measure quality of life among older people. Aging Clin Exp Res 2007;19:457-64.

33. Shores M, Matsumoto A. Current opinion in endocrinology. diabetes and obesity 2015;21:209-16.

34. Travison TG, Vesper HW, Orwoll E, et al. Harmonized reference ranges for circulating testosterone levels in men of four cohort studies in the united states and europe. J Clin Endocrinol Metab 2017:102:1161-73

35. O'Connell MD, Tajar A, Roberts SA, et al. Do androgens play any role in the physical frailty of ageing men? Int J Androl 2011;34:195-211.

36. Casaburi R, Bhasin S, Cosentino L, et al. Effects of testosterone and resistance training in men with chronic obstructive pulmonary disease. Am J Respir Crit Care Med 2004;170:870-8.

37. Roy CN, Snyder PJ, Stephens-Shields AJ, et al. Association of testosterone levels with anemia in older men: a controlled clinical trial. JAMA Intern Med 2017;177:480-90.

38. Cawthon PM, Ensrud KE, Laughlin GA, et al. Osteoporotic Fractures in Men (MrOS) Research Group. Sex hormones and frailty in older men: the osteoporotic fractures in men (MrOS) study. J Clin Endocrinol Metab 2009;94:3806-15.

39. Teh R, Kerse N, Kepa M, et al. Self-rated health, health-related behaviours and medical conditions of maori and non-maori in advanced age: LiLACS NZ. N Z Med J 2014;127:1397. 